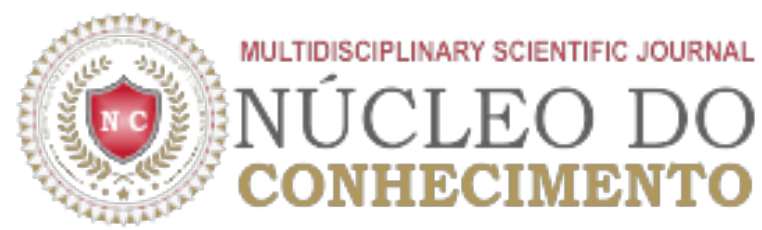

\section{A Atuação do Assistente Social no Acolhimento ao Paciente Oncológico}

\author{
SILVA, Dulciléia Martins da ${ }^{[1]}$, DENDASCK, Carla Viana ${ }^{[2]}$, OLIVEIRA, Euzébio de ${ }^{[3]}$
}

SILVA, Dulciléia Martins da; et.al. A Atuação do Assistente Social no Acolhimento ao Paciente Oncológico. Revista Científica Multidisciplinar Núcleo do Conhecimento. Edição 8. Ano 02, Vol. 05. pp 39-51, Novembro de 2017. ISSN:2448-0959, Link de acesso: https://www.nucleodoconhecimento.com.br/saude/paciente-oncologico, $\quad$ DOI: 10.32749/nucleodoconhecimento.com.br/saude/paciente-oncologico

\section{RESUMO}

Objetivo: analisar a intervenção do profissional de Serviço Social ao paciente da área de Oncologia, haja vista a problemática relacionada ao tema, ou seja, as dificuldades encontradas por pacientes acometidos por câncer na adaptação à internação e ao tratamento da doença, considerando-se que o câncer é ainda considerada uma doença estigmatizante. Metodologia: foi realizado um estudo de revisão bibliográfica entre os anos de 2010 a 2015. Resultados: o câncer é uma doença estigmatizante, que dá margem a um processo de significação, gerado pela percepção de que a doença possibilita a reformulação de preconcepções e a elaboração de novos conceitos sobre ter uma doença incurável; cuidar do paciente com câncer implica em ter conhecimento em relação à patologia, bem como aprender a lidar com os sentimentos desses pacientes e com as suas próprias emoções perante a doença, bem como de seus familiares; a intervenção do Serviço Social tem o objetivo de proporcionar acolhimento, atendimento e acompanhamento social e, assim, identificam-se problemas que possam vir a comprometer o tratamento da doença, bem como afetar a vida do paciente e de seus familiares. Conclusões: A atenção do Serviço Social possibilita melhoria da qualidade de vida de pacientes oncológicos, pois a atenção ao paciente de uma doença que provoca mudanças significativas no comportamento dos indivíduos gera necessidades a serem atendidas e, assim, o Assistente Social exerce intervenção fundamental na colaboração para a melhoria da qualidade de vida da pessoa acometida pela doença a partir da compreensão da experiência da pessoa com câncer e o adequado acolhimento e apoio ao indivíduo e a seus familiares.

Palavras-Chave: Paciente Oncológico, Assistente Social, Acolhimento.

\section{INTRODUÇÃO}


A questão da saúde na sociedade brasileira tem sofrido um processo de alterações em sua dimensão política e social, a partir da introdução de um conjunto de medidas e processos que contribuíram para modificar a relação da entidade hospitalar com o paciente. Dessa forma, a atenção ao indivíduo sujeito a tratamentos e/ou internações hospitalares ou ambulatoriais tem exigido dos profissionais a atenção necessária em prol da qualidade de vida do paciente (INCA, 2016).

Dentre os profissionais incluídos nesse processo de alterações na dimensão política e social está o Assistente Social que presta a complementaridade da atenção ao paciente da área de Oncologia (INCA, 2016). E nesse contexto a atuação do Serviço Social está voltada para o atendimento do usuário em suas necessidades psicossocial e emocional, em situações de doença, norteado pelo compromisso de valorização da dignidade da pessoa humana, compreendendo a pessoa doente, assim como sua enfermidade, para tratá-la como ser completo que pertence a uma família e a uma comunidade, dentro de uma perspectiva de acolhimento do doente e de seu familiar (BRENTANI, 2013).

O doente de câncer, o paciente oncológico apresenta uma vasta gama de necessidades afetadas, principalmente as de ordem emocional e os aspectos emocionais na doença, devendo-se prestar-lhe o adequado acolhimento e assisti-lo da melhor forma possível, orientando nos encaminhamentos necessários, além de prestar-lhe apoio tanto no físico como no psicológico, já que a saúde é uma interação de equilíbrio entre corpo e mente, o qual interfere significativamente nas respostas ao tratamento do câncer (BERLINGUER, 2008).

O câncer, após as doenças cardiovasculares, é atualmente a segunda causa de morte no mundo ocidental, especialmente nos países desenvolvidos. Os pesados investimentos em pesquisas e o volume de trabalhos publicados na área de oncologia confirmam, nos últimos anos, a importância atribuída à doença. Em tal cenário, a Organização Mundial de Saúde (OMS, 2014) dispõe que onze milhões de pessoas são diagnosticados com câncer anualmente e que a doença representa $12,5 \%$ das mortes no mundo. Segundo a OMS, mais de 16 milhões de casos serão verificados até 2020.

O Instituto Nacional do Câncer (INCA), do Ministério da Saúde, descreve que, analisando-se as taxas de mortalidade no Brasil, o câncer está sempre incluído entre as primeiras causas de morte (INCA, 2016).

Assim, cada vez mais, vivencia-se o aumento significativo das neoplasias malignas. No quadro sanitário brasileiro, esta realidade tem ampliado a discussão sobre o controle desse grupo de doenças, incluindo-as como uma das prioridades em saúde. Apesar de ainda haver áreas obscuras na compreensão da etiologia do câncer, já se tem conhecimentos suficientes para embasar ações de controle capazes de diminuir sua incidência e mortalidade (INCA, 2016).

Dessa forma, justifica-se a escolha da temática por ser o câncer uma doença em que, frequentemente a primeira atitude do doente ao receber a notícia é a negação, no segundo momento é angústia, sensação de vazio, abandono e medo da morte, perante a qual o paciente necessita de apoio de toda a equipe de saúde, na qual se inclui o Assistente Social e, fundamentalmente, do apoio da família, esta que é também fortemente impactada pela notícia da doença.

Diante do exposto, o objetivo deste artigo foi analisar a intervenção do profissional de Serviço Social ao paciente da área de Oncologia, haja vista a problemática relacionada ao tema, ou seja, as dificuldades 
encontradas por pacientes acometidos por câncer na adaptação à internação e ao tratamento da doença, considerando-se que o câncer uma doença ainda estigmatizante.

\section{METODOLOGIA}

Para atender ao objetivo proposto foi desenvolvido o procedimento metodológico de pesquisa bibliográfica que, segundo Richardson (2010), é importante por ser um método que implica na seleção, leitura e análise de textos relevantes ao estudo e tem por base fundamentos que determinam os passos e o caminho a ser percorrido na pesquisa, assim como exige reflexão constante e controle de variáveis, checando-se informações em relação ao conhecimento já adquirido. Segundo o autor, na realização da pesquisa bibliográfica é importante que o pesquisador faça um levantamento dos temas e tipos de abordagens já trabalhadas por outros teóricos, assimilando os conceitos e explorando os aspectos já publicados.

Dessa forma, foi realizado um estudo de revisão bibliográfica e, para a pesquisa, foram utilizados livros, artigos científicos encontrados em sites de pesquisa, publicados entre os anos de 2010 a 2016, tais como Lilacs e Scielo, utilizando-se como descritores os termos: câncer, assistente social e acolhimento.

\section{RESULTADOS E DISCUSSÃO}

\section{O CÂNCER COMO UMA DOENÇA MULTIFATORIAL}

Segundo Borges et al. (2006), câncer é o nome genérico de um conjunto de mais de 200 doenças distintas, com multiplicidade de causas, formas de tratamento e prognósticos. Várias transformações podem ocorrer na mesma célula, fazendo com que ela se prolifere rapidamente e se transforme em uma massa tumoral. Portanto, o câncer nada mais é que a multiplicação descontrolada de células defeituosas ou atípicas, que escapam ao controle do sistema imunológico por algum motivo até hoje desconhecido.

Neiva (2014) cita que o câncer é uma doença que está cada vez mais próxima da realidade do brasileiro e expõe que o Instituto Nacional do Câncer (INCA) demonstra que são esperados 576 mil novos casos de câncer no Brasil para os próximos dois anos, sendo 8.603 casos somente no estado do Pará.

Para Berlinguer (2008), muitas das causas do câncer estão relacionadas ao estilo de vida de uma pessoa, pois o câncer é uma doença que muitas vezes se desenvolve sem dar sinais claros de sua existência, além do que muitas pessoas pensam que, se ela não tem sintomas, não estão doentes ou não estão adoecendo e, nesse sentido, a maioria não compreende o conceito de que o câncer, em geral, pode levar vários anos para se desenvolver.

Segundo Berlinguer (2008), podem ser encontrados no ambiente físico, ser herdados ou representar hábitos ou costumes próprios de um determinado ambiente social e cultural. $\mathrm{O}$ surgimento de um câncer em uma pessoa não depende de um único fator de risco na grande parte das vezes. As pesquisas realizadas pelos cientistas já conseguiram mostrar que um conjunto de fatores atua sobre determinada pessoa para que a doença oncológica possa aparecer (BERLINGUER, 2008).

\section{O CÂNCER COMO DOENÇA ESTIGMATIZANTE}


Almeida et al. (2010) afirmam que o câncer é uma doença estigmatizante, que dá margem a um processo de significação, gerado pela percepção de que a doença possibilita a reformulação de preconcepções e a elaboração de novos conceitos sobre ter uma doença incurável.

Segundo os autores, a interpretação da experiência de viver com a doença oncológica e seu tratamento gera sentimentos e atitudes que refletem um grau de incerteza a partir da revelação do diagnóstico e das suas concepções a respeito da doença, suas possibilidades de recorrência e causalidade, representando "uma visão assustadora e temerosa e que desperta temor", pois o ocultamento dos sinais e sintomas físicos dificulta um diagnóstico precoce, o que é percebido como o lado sombrio da doença, além da possibilidade de sua recorrência, visto ser ela imprevisível (ALMEIDA et al., 2010, p. 64).

O sofrimento embutido na experiência de cada uma também é revelado como algo que marca profundamente suas vidas, da mesma forma que mostra a possibilidade da recorrência que é incorporada como parte do processo de adoecer (ALMEIDA et al., 2010, p. 65).

Nesse sentido, as pessoas vitimadas pelo câncer buscam identificar sentimentos e para tal tentam compreender sua própria responsabilidade no processo de adoecer, assim como passam a conviver com uma nova concepção de si mesmas, a qual nem sempre é facilmente aceita e, desse modo, tendem a se comportar como pessoas com um estigma particular que tendem a vivenciar experiências similares de aprendizagem, relativas à sua condição e a sofrer mudanças análogas na concepção do eu, que não sejam apenas causa, mas também efeito do compromisso com uma sequência semelhante de ajustamentos pessoais, em que ao enfrentarem a doença adquirem o sentido de conviver com sentimentos negativos através da culpa e autocensura, percebendo-se com alterações corporais (FIGUEIREDO, 2009).

Para o autor, diante da situação vivida, muitas pessoas passam a refletir acerca das ações tomadas com relação à sua saúde e percebem o descaso que tiveram com o próprio corpo. Aqueles que se encontram numa fase avançada da vida passam por uma reorganização radical da visão do seu passado, sustentando Figueiredo (2009, p. 68) que o doente de câncer "passa a refletir sobre todos os erros cometidos no passado".

Segundo Laplantine (2008), o câncer, simbolicamente representado no imaginário popular pelas crenças tradicionais sobre a natureza moral da saúde, da doença e do sofrimento humano traz para as pessoas acometidas dificuldades para elaborar uma imagem satisfatória da doença, visto que é percebida por todos como o próprio mal; além de a doença ser constantemente associada como a perda do poder físico ou da dignidade humana, fato que se traduz na prepotência dos sadios e que acentua a desigualdade social, que acentua o constrangimento por serem portadoras de uma doença impregnada de preconceitos.

O constrangimento de ter uma doença estigmatizante leva alguns doentes a se afastarem das pessoas de seu convívio social. Essa atitude parece fruto de um processo interpretativo, baseado nos seus conceitos e nos dos outros sobre a doença, que deliberadamente escondem informações sobre sua identidade social verdadeira, quer recebendo ou aceitando um tratamento baseado em falsas suposições a seu respeito. A manipulação da informação oculta que desacredita o eu, ou seja, o encobrimento da doença é evidenciado no enfrentamento da situação vivida por pessoas doentes (GUALDA, 2008, p. 98).

Para Simonetti (2008), o recebimento do diagnóstico de uma doença grave como o câncer possui as seguintes fases: 
- Fase 1 - Reacional: a doença é um evento em que tudo o mais perde importância ou passa a girar em torno dela, resultando em negação, revolta, depressão e enfrentamento (sem ordem fixa);

- Fase 2 - Negação: é a primeira reação diante da doença, sendo diferente de desconhecimento, variando de forma e ocorrendo por falta de condições psicológicas da pessoa doente;

- Fase 3 - Revolta: é a reação dirigida contra a doença, o médico, os enfermeiros, a família, pois para o doente a situação de doença não é justa, se caracterizando pela frustração, raiva e depressão, em vista das limitações impostas pela doença. Possui estreita ligação com a reação de agitação (choros, gritos e agressões), em decorrência da injustiça da doença, que é entendida como um castigo. No entanto, se caracteriza, também, como um estado de estresse, que é um estado de prontidão para a luta.

- Fase 4 - Depressão: é a entrega passiva à doença, em sinal de desistência, desesperança na cura e tristeza, em que o silêncio é mais comum. Pode chegar ao nível patológico em vista da melancolia e do sentimento de luto e impotência, principalmente perante uma doença grave.

- Fase 5 - Enfrentamento: É uma reação às outras posições, uma mistura entre a luta e o luto, uma polaridade e uma estratégia humana para lidar com mudanças, em decorrência do adoecimento e em busca de soluções do tipo realista, misturando potência e impotência em relação à doença e, dessa forma, não negar a doença. É uma posição de fluidez emocional partilhada com a família.

Para Almeida et al. (2010), no entanto, o preconceito identificado por portadores de doença oncológica explicita também a possibilidade da recorrência da doença, quando trazem em seu discurso a falta de credibilidade na cura. A interpretação dessa possibilidade está baseada na construção social da doença, na realidade vivenciada, ou seja, o câncer ainda é uma doença fundamentalmente incurável; portanto, seu futuro passa a ser incerto.

Assim, pode-se afirmar que viver com uma doença estigmatizante, conviver com sentimentos negativos e enfrentar preconceitos significa se deparar, constantemente, com incertezas e possibilidades da recorrência da doença, momento em que se constata a importância não somente dos profissionais de saúde, mas também da família do doente, por significarem o entendimento de como as pessoas percebem o significado do câncer e suas formas de enfrentamento, com o fim de ajudá-las a explorar seus sentimentos, expectativas e estratégias de ajustamento e suporte constante, com vistas a equilibrarem as complexas conexões entre a doença, sentimentos de incerteza a partir da experiência da doença (SIMONETTI, 2008).

Observa-se que o tratamento do câncer é longo e com grande desgaste emocional e físico e requer persistência e esperança do paciente e da família. Toda a doença é uma situação traumática e com o câncer não é diferente. É uma doença que traz consigo o estigma da morte e a relação equipepaciente mostra-se com características bem diferentes de situações menos graves. Portanto, é fundamental uma equipe que se compadeça e que tenha competência técnica para lidar com as diversas fases da doença oncológica (ALMEIDA et al., 2010).

\section{IMPACTO PSICOSSOCIAL DO PACIENTE COM CÂNCER E A IMPORTÂNCIA DO PROFISSIONAL DA SAÚDE}


Para Simonetti (2008), tais fases ocorrem em vista de o câncer se caracterizar como uma doença associada à dor, morte e sofrimento, desesperança, medo, ansiedade e perda do controle. A dor é uma experiência emocional e sensorial desagradável, associada a uma lesão tecidual real, quando associada ao câncer. A exacerbação da percepção dolorosa é uma das complicações mais temidas, por quem sofre ou já sofreu com essa doença. O sofrimento doloroso pode desencadear alterações emocionais, culturais e psicológicas.

O autor também cita que elementos sensoriais, afetivos, culturais e emocionais compõem o fenômeno doloroso, o qual não implica apenas na veiculação da informação sensitiva através das vias nervosas até seu processamento no sistema nervoso central. Atualmente, há interação entre as diferentes qualidades sensoriais e a dolorosa e entre esta e os sistemas responsáveis pelos aspectos cognitivos e afetivos do indivíduo.

Em tal cenário, Rodrigues (2009) pontua que cuidar do paciente com câncer implica em ter conhecimento em relação à patologia, bem como aprender a lidar com os sentimentos desses pacientes e com as suas próprias emoções perante a doença.

Para o autor, o processo de cuidar ameniza e alivia a dor. Aspectos como a comunicação entre a família, o paciente e principalmente a equipe de saúde (que muitas vezes se sentem impotentes e acabam se afastando para não ter que responder questionamentos da família ou do paciente, pois é muito difícil relatar a gravidade do caso e dizer que se está apenas aguardando a morte) são muito importantes. É, pois, fundamental manter o controle de sintomas, como a dor, os aspectos bioéticos, principalmente a autonomia, a veracidade, a beneficência e o acolhimento.

Além dos problemas trazidos pela própria doença, o paciente ainda está exposto à hospitalização, que se torna em uma nova situação por ser um espaço desconhecido, sendo importante que o local e o tratamento sejam dignos, humanos e acolhedores, possibilitando a redução das angústias e medos do doente, bem como de seus familiares.

A família de um paciente com neoplasia requer atenção, devido à cronicidade e agravos da patologia, conjugada com o tempo em que fica exposta a essa situação de sofrimento extremo (KOVÁCS, 2008). Quanto mais avançada a doença, maior é o nível de dependência do paciente em relação à família, tornando-se necessário identificar os cuidados, considerando as dificuldades que serão enfrentadas pelos familiares nesse processo; oferecendo suporte às situações de desgaste físico e emocional que o problema impõe no momento de enfrentamento das muitas situações limites que se apresentam nesse cotidiano do cuidar de pacientes em tratamentos paliativos.

\section{A ATUAÇÃo DO ASSISTENTE SOCIAL NO ACOLHIMENTO AO PACIENTE ONCOLÓGICO}

O Serviço Social, segundo Martinelli (2012), é uma profissão de natureza eminentemente interventiva que atua no campo das relações humano-sociais. É uma forma de especialização do trabalho coletivo, socialmente construído. Participa do processo global de trabalho e tem, portanto, uma dimensão sóciohistórica e política que lhe é constitutiva e constituinte.

Segundo o autor, o Assistente Social é o profissional que, preferencialmente, é chamado a implementar 
políticas sócio-assistenciais no interior das organizações públicas governamentais e não-governamentais, das organizações privadas, operando sob duas perspectivas: a prestação de serviços e a ação educativa.

$\mathrm{Na}$ área da saúde, o Serviço Social se amplia por meio do novo conceito de saúde elaborado em 1948 pela Organização Mundial de Saúde (OMS), tendo como foco os aspectos biopsicossociais, dos quais promovem ao assistente social uma tarefa educativa com intervenção normativa no modo de vida da "clientela", com relação aos hábitos de higiene e saúde, atuando assim nos programas prioritários estabelecidos pelas normatizações da política de saúde (BRAVO; MATOS, 2011).

Os autores observam que a capacitação profissional influencia a qualidade dos serviços, a qualidade da prática do Serviço Social, por isso devem estar sempre atualizados e comprometidos com seu fazer profissional, inseridos em cursos, palestras, oficinas na busca de novos conhecimentos para melhor atender os usuários. Portanto, fica claro que o novo perfil do Assistente Social adere às exigências de uma capacitação teórico-metodológica, ético-política e técnico-operativa.

O Assistente Social, inserido na área da Saúde, tem a contribuir na direção da objetivação dos direitos sociais e na construção de novos sujeitos coletivos que realizem seus direitos. Assim, percebe-se que o agir profissional do Assistente Social que atua na área da Saúde não se restringe apenas às demandas no que diz respeito à saúde do usuário, mas sim nas expressões da questão social, principalmente quanto ao acolhimento do usuário doente.

A intervenção do Serviço Social tem o objetivo de proporcionar acolhimento, atendimento e acompanhamento social, por exemplo, aos pacientes internados e seus respectivos familiares e/ou acompanhantes, dentro de uma perspectiva crítica, por meio do desdobramento clínico da questão social postas ao Serviço Social durante o período de internação.

O assistente social está preparado para acrescentar na relação com o paciente, elementos que possibilitem o enfrentamento de sua condição de pessoa doente, sua relação com a família [...] a continuidade do tratamento e outras condições chamadas "sociais", vitais ao SUS e à sobrevivência, que são de seu domínio profissional (BERTANI, 2013, p. 43).

Segundo Martinelli (2012), o Assistente Social muito contribui, por exemplo, com o paciente doente de câncer e seus familiares, a partir das seguintes ações:

- Atendimento/ acolhimento individual a pacientes;

- Atendimento/ acolhimento a acompanhantes/familiares;

- Intervenção sobre internação (admissão social);

- Procedimento de interconsulta com equipe de saúde;

- Intervenção interprofissional (articulações internas);

- Articulação interinstitucional; 
- Encaminhamento à rede de serviços - interna e externa;

- Atendimento e visita domiciliar;

- Orientação sobre Tratamento Fora de Domicílio (TFD).

O autor relaciona ainda o acolhimento e orientação em razão de óbito; orientação referente à acompanhante; orientação sobre benefício assistencial e identificação da rede familiar, pois o campo de ação do Serviço Social implica um contato direto com o paciente e sua família, a partir de investigações de situações culturais, ambientais, sociais, pessoais, psicológicas e financeiras do paciente. Dessa forma, identificam-se problemas que possam vir a comprometer o tratamento da doença, bem como afetar a vida do paciente e de seus familiares.

O profissional do Serviço Social, segundo Gualda (2008), com objetivos de minimizar os impactos psicológicos e emocionais que envolvem o paciente com câncer, pode instituir as seguintes ações:

a) Orientação e informação sobre a instituição hospitalar e seus recursos;

b) Orientação e encaminhamento a serviços e recursos previdenciários;

c) Realização de contato com o paciente e sua família;

d) Interpretação dos fatores sociais, políticos e econômicos que permeiam a realidade dos pacientes e de seus familiares;

e) Orientação do tratamento global nos aspectos biopsicossociais;

f) Realização de trabalho integral, multidisciplinar, com os membros da equipe de saúde.

O papel do Assistente Social no acompanhamento dos pacientes da área oncológica ocorre mediante o levantamento do perfil biopsicossocial do paciente e de orientações sobre o tratamento da doença e promoção de ações educativas, que visam "desencadear um processo reflexivo nos pacientes e familiares, para que possam participar do processo de tratamento e/ou cura" (GUALDA, 2008, p. 7).

Do mesmo modo, o suporte fornecido pelo Serviço Social oferece apoio psicossocial a partir de informações que ajudam a desmistificar a doença (câncer); contribuições para que o doente seja capaz de enfrentar a doença, bem como ações sociais relativas ao tratamento e reabilitação do doente oncológico.

Gualda (2008) confirma que a necessidade de intervenção social para o doente visa à humanização dos procedimentos a fim de que o indivíduo doente reelabore seu estado emocional e lide com a doença de maneira menos agressiva possível. Nesse sentido, o Assistente Social, como profissional de Saúde, possui competências para intervir junto aos fenômenos socioculturais (emocionais e comportamentais) que contribuem para a melhoria da qualidade de vida de doentes oncológicos. Portanto, todos os profissionais envolvidos na área da saúde devem se preocupar com o ser humano, assim como têm que desenvolver meios para oferecer a oportunidade de uma existência mais digna, mais compreensiva e menos solitária no momento da doença.

É muito importante que os profissionais atuantes na área da saúde (médicos, enfermeiros e assistentes sociais) se conscientizem de que o homem é muito mais do que uma entidade biológica, pois ele possui um mundo interior que não pode ser ignorado, sendo a relação entre a mente, o corpo e os sentimentos, dinâmica e interdependente, podendo uma influenciar e afetar as outras. Além da conscientização, que 
seria o ponto de partida, há a necessidade de os profissionais refletirem e mudarem sua forma de conceber o doente oncológico, valorizando suas experiências e inquietações a respeito da doença e do seu contexto sociocultural, para poderem prestar-lhe assistência que vise melhoria de sua qualidade de vida.

\section{CONCLUSÃO}

Esta pesquisa abordou a prática profissional do Assistente Social dentro da área da saúde, especificamente a intervenção do profissional de Serviço Social ao paciente da área de Oncologia e a análise desenvolvida apresenta que a atuação desse profissional se pauta nos interesses dos usuários, buscando principalmente a garantia de direitos sociais, de modo que esses profissionais devem possuir amplo conhecimento, visando garantir o acesso à rede de serviços (consultas, cirurgias, acompanhamento ambulatorial, entre outros serviços) para a população usuária.

Diante de todo o exposto, conclui-se que o profissional Assistente Social deve possuir as competências e habilidades necessárias para atuação junto ao paciente da área oncológica, haja vista também atuar em conjunto com equipe multidisciplinar na elaboração de planos referentes ao atendimento e atenção ao paciente em nível individual ou familiar.

Dessa forma, a atenção do Serviço Social possibilita melhoria da qualidade de vida de pacientes oncológicos, pois a atenção ao paciente de uma doença que provoca mudanças significativas no comportamento dos indivíduos gera necessidades a serem atendidas e, assim, o Assistente Social exerce intervenção fundamental na colaboração para a melhoria da qualidade de vida da pessoa acometida pela doença a partir da compreensão da experiência da pessoa com câncer e o adequado acolhimento e apoio ao indivíduo e a seus familiares.

\section{REFERÊNCIAS}

ALMEIDA, Ana Maria de; MAMEDE, Marli Villela; PANOBIANCO, Marislei Sanches; PRADO, Maria Antonieta Spinoso; CLAPIS, Maria José. Construindo o significado da recorrência da doença: a experiência de mulheres com câncer de mama. Escola de Enfermagem de Ribeirão Preto da Universidade de São Paulo, 2010.

BERLINGUER G. A doença. São Paulo (SP): Hucitec, 2008, 151 p..

BORGES, A. D. V. S. et al. Percepção da morte pelo paciente oncológico ao longo do desenvolvimento. Psicologia em Estudo, Maringá, v. 11, n. 2, maio/ago, 2006.

BRAVO, Maria Inês Souza; MATOS, Maurílio Castro de Matos. Projeto Ético-Político do Serviço Social e sua relação com a Reforma Sanitária: elementos para o debate. São Paulo: Cortez, 2011.

BRENTANI, Marcelo M.; COELHO, Fernando R. G.; KOWALSKI. Bases da Oncologia. São Paulo: Lemar Livraria; Editora Marina e Tecmed Editora, 2013.

FIGUEIREDO, E. M. A. A doença oncológica. Rio de Janeiro: REVINTER, 2009.

GUALDA, Judith. A compreensão da doença e do doente. Porto Alegre: Artes Médicas, 2008. 
INSTITUTO NACIONAL DO CÂNCER - INCA. Causas e tratamento do câncer. 2016. http://www2.inca.gov.br/wps/wcm/connect/tiposdecancer/site/home/estomago/prevencao. Acesso em 09 de abril de 2016.

LAPLANTINE, F. Antropologia da doença. São Paulo (SP): Martins Fontes, 2008.

MARTINELLI, Maria Lúcia. Serviço Social: identidade e alienação. São Paulo: Cortez, 2012.

NEIVA, Cristina Barros. Câncer e mudança de hábito. Belém: Ofir Loyola, 2014.

RICHARDSON, R.J. Pesquisa bibliográfica: métodos e técnicas. Santos: Atlas, 2010.

RODRIGUES, I. G. Cuidados paliativos: análise de conceito. Ribeirão Preto: Universidade de São Paulo: Escola de Enfermagem de Ribeirão Preto, 2009.

SIMONETTI, Alfredo. Manual de Psicologia Hospitalar: o mapa da doença. São Paulo: Casa do Psicólogo, 2008.

[1] Assistente Social. Especialista em Oncologia Multiprofissional pela Universidade de Jales - Unijales

[2] Doutora em Psicanálise- Pesquisadora do Centro de Pesquisas e Estudos Avançados- CEPA

[3] Biólogo. Doutor em Medicina/Doenças Tropicais. Docente e Pesquisador na Universidade Federal do Pará - UFPA. Pesquisador no Laboratório de Toxicologia Humana e Ambiental e no Laboratório de Estresse Oxidativo do Núcleo de Medicina Tropical da UFPA (NMT-UFPA)

\section{PUBLIQUE SEU ARTIGO CIENTÍFICO EM:}

https://www.nucleodoconhecimento.com.br/enviar-artigo-cientifico-para-submissao 